Thorax, 1981, 36, 319-320

\title{
Correspondence
}

\section{Intrapleural immunotherapy with Corynebacterium parvum in recurrent malignant pleural effusion}

Sir,- Since the techniques described by the authors of the article in your November 1980 issue $^{1}$ for the treatment of recurrent malignant pleural effusions with intrapleural Corynebacterium parvum or intrapleural mustine were not strictly comparable, some of your readers may not accept the view that $C$ parvum is a more effective suppressant agent than mustine for that purpose.

It is stated that after "complete" aspiration of pleural fluid one group of patients received an intrapleural instillation of mustine and the other an intrapleural instillation of $C$ parvum. Firstly, I believe that it is safe to inject mustine into the pleural space only when a few hundred millilitres of fluid are still present; otherwise there is a danger that this corrosive substance will enter the lung or the extrapleural tissues. Secondly, mustine produces a brisk exudative reaction, invariably accompanied by an increase in the size of the effusion. It is usually assumed that this reaction reaches a maximum after about 24 hours, and that it is then essential to drain all the fluid from the pleural space, preferably through a basal intercostal tube, to ensure that the lung re-expands completely and brings the inflamed pleural surfaces into apposition at the time they are most likely to become adherent. This effect can be achieved by irritant substances other than mustine and there is very little evidence that any specific action of mustine on malignant cells will prevent recurrence of an effusion unless the pleural space is obliterated. The authors do not appear to have adopted this policy in their mustine-treated patients. Indeed, they state that a second dose of mustine was injected into the pleural space "if repeat aspiration proved necessary." No mention is made of intercostal drainage, which is generally regarded as a prerequisite to successful "mustine pleurodesis", and that could well explain the five failures in the mustinetreated group of patients.

Although I would question the validity of the comparison made in the article between the two forms of treatment, I was most impressed by the results obtained with intrapleural $C$ parvum. Since these were achieved without subsequent drainage of all the pleural fluid, it would seem that $C$ parvum specifically prevented recurrence of the effusions. If these results can be reproduced in a larger series, it would clearly become the treatment of choice for malignant pleural effusion.

IAN WB GRANT

Respiratory Unit

Northern General Hospital

Edinburgh

\section{Reference}

1 Millar JW, Hunter AM, Horne NW. Intrapleural immunotherapy with Corynebacterium parvum in recurrent malignant pleural effusions. Thorax $1980 ; 35: 856-8$.

Sir,-Dr Grant has commented on the technique of mustine instillation which we employed in our study of recurrent malignant effusions. The instillation of mustine after complete aspiration of the malignant effusion as we described is in accordance with the early descriptions of the usage of mustine, ${ }^{12}$ and we noted no immediate complications, in particular no evidence of intrapulmonary or extrapleural extravasation which can be avoided by careful technique. We were anxious to employ the same technique for mustine and $C$ parvum instillation so that direct comparison could be made particularly with regard to morbidity and patient tolerance. Although several authors ${ }^{12}$ and a recent review article ${ }^{3}$ recommend subsequent routine drainage of any residual pleural fluid 24 hours after mustine instillation either by repeat aspiration or through a basal intercostal tube, the success rates for suppression of reaccumulation of pleural fluid in their series at $24 / 32(75 \%)$ and $18 / 30$ $(60 \%)$ are not strikingly superior to the success rate of $6 / 11(55 \%)$ which we recorded in an admittedly small number of patients with mustine instillation alone.

In the 10 patients we reported who received $C$ parvum and who survived long enough to assess their response, complete suppression was obtained in eight patients and partial in two patients. Although these numbers are small, this and our subsequent experience of $C$ parvum in five further patients indicate that it is an effective suppressive agent which is well tolerated apart from a rather prolonged febrile reaction which we have noted in two of the patients treated recently. Long-term follow-up of this admittedly small number of patients has shown more prolonged mean survival (180 days) compared with mustine-treated patients ( 90 days), and we are currently studying the effect of repeated $C$ parvum instillation on survival. The simplicity of $C$ parvum instillation is a major advantage when compared to prolonged intercostal drainage, and we believe that our results with $C$ parvum indicate that it is as effective as any reported study of mustine with or without intercosal drainage and is certainly better tolerated by the patient.

JW MILLER, AM HUNTER, NW HORNE Chest Unit and University Department of Respiratory Diseases, City Hospital, Edinburgh 


\section{References}

1 Mark JBD, Goldenberg IS, Montague AC. Intrapleural mechloroethamine hydrochloride therapy for malignant pleural effusion. JAMA 1964; 187: $858-60$.

2 Weisberger AS, Levine B, Storaasli JP. Use of nitrogen mustard in the treatment of serous effusions of neoplastic origin. JAMA 1955; 159: $1704-7$.

3 Friedman MA, Slater E. Malignant pleural effusions. Cancer Treat Rev 1978; 5:49-65.

\section{Nebulised salbutamol}

Sir,-The paper by Wilson and Connellan in your November 1980 issue $^{1}$ demonstrated that nebulised salbutamol given at home to patients with chronic bronchitis and emphysema was significantly better than placebo. This is not surprising since the dose they gave was $5 \mathrm{mg}$ which is 50 times greater than a single dose from a metered aerosol. It would be more relevant clinically to compare the metered aerosol for two weeks in conventional dosage with nebulised salbutamol.

However, I am really writing to point out that because large doses of nebulised salbutamol cause brochodilatation it does not necessarily follow that their widespread use is advisable. Almost certainly the medihaler iso forte caused similar degrees of bronchodilatation, but it may also have caused an increased number of deaths in asthmatic patients. A cause and effect relationship was never proved but in view of the circumstantial evidence it would be sensible to recognise at least the possibility that large doses of salbutamol may have similar consequences. I am aware of one 14-year-old asthmatic boy who died at home recently five minutes after inhaling a similar dose of nebulised salbutamol. Obviously one case tells us nothing more than to be aware of a possible association, though I would be interested to hear of any similar occurrences.

I am not suggesting that nebulised salbutamol should not be given at home, but it should be given in the knowledge that little is known about the longterm consequences and there may be a risk involved. Further work is needed to assess the long-term effects of this treatment. Until this is done care should be taken in recommending it on the basis of short-term studies on small numbers of patients where benefit is assessed but not long-term risk.

ANNE TATTERSFIELD University of Southampton Faculty of Medicine Southampton General Hospital Southampton

\section{Reference}

1 Wilson RSE, Connellan SJ. Domiciliary nebulised salbutamol solution in severe chronic airway obstruction. Thorax 1980; 35:873-6.

Sir,- I agree that the effect of nebulised salbutamol in our study is dependent on the dose given. The group of patients studied had all received regular conventional therapy from a metered aerosol without symptomatic benefit, and the question asked was whether in this group with severe airway obstruction large doses of inhaled bronchodilator was more effective than nebulised water. Not surprisingly, it did prove more beneficial, although when the study was undertaken some two and a half years ago many colleagues were sceptical about this. I would agree that comparison of drug dosage against drug dosage in this type of patient would be valuable, but feel that the use of nebulised respirator solution provides a useful and convenient way of delivering large doses of bronchodilator to the airways of patients who can be shown to benefit. I agree that we need to know more about the long-term risk of patients using nebulised bronchodilators, and would be against widespread use of such therapy. However, I feel that there are certain patients who should be considered for nebuliser therapy when conventional therapy has not been beneficial.

We have about 80 patients, mostly with chronic bronchitis and emphysema, on regular domiciliary therapy and have been running a nebuliser service for three and a half years. Inevitably, deaths among this largely elderly group with severe airway obstruction and respiratory failure have occurred-but we have not been able to implicate nebulised salbutamol as a cause.

RSE WILSON

Royal Shrewsbury Hospital Mytton Oak Road Shrewsbury 